\title{
OPTIMIZATION OF A TURBINE USED IN COAL FIRED THERMAL POWER PLANTS BASED ON INLET STEAM TEMPERATURE USING THERMOECONOMICS
}

\author{
Mukesh Gupta ${ }^{1}$ and Raj Kumar ${ }^{2}$ \\ ${ }^{1,2}$ Department of Mechanical Engineering, YMCA University of Science \& Technology \\ Faridabad, Haryana, India
}

\begin{abstract}
The purpose of current study is to analyze the effect of inlet steam temperature coming from the boiler on thermoeconomic performance of a steam turbine used in a coal fired thermal power plant. Second law of thermodynamics is used to develop the thermoeconomic model for the turbine. Analyses based on exergetic and exergoeconomic criteria are done for the turbine used in a $210 \mathrm{MW}$ power plant. Methodology is explained with the help of an example. Effect of inlet steam temperature on the exergetic efficiency of the turbine, unit product cost of turbine and unit product boiler has been shown. Optimization has been done for the turbine as a trade off between the unit product cost of inlet steam from the boiler and unit product cost of the turbine.
\end{abstract}

\section{Keywords}

Thermoeconomic Evaluation, Exergy costing, Turbine System \& Exergetic Efficiency

\section{INTRODUCTION}

A steam turbine is a device that extracts thermal energy from pressurized steam and uses it to do mechanical work on a rotating output shaft, which is further used to generate electricity. The steam turbine is a form of heat engine that derives much of its improvement in thermodynamic efficiency from the use of multiple stages in the expansion of the steam, which results in a closer approach to the ideal reversible expansion process. Steam turbines are heart of power plant as they are the devices which transform thermal energy in fluid to mechanical energy. Non-linear simplex direct search method has been used to improve the performance of gas turbine cogeneration systems [1]. Detailed thermodynamic, kinetic, geometric, and cost models have been developed, implemented, and validated for the synthesis/design and operational analysis of hybrid SOFC-gas turbine-steam turbine systems [2]. Several thermodynamic relations have been developed to illustrate the relationship between the energy and exergy losses and capital cost for thermal systems in a modern coal fired electrical generation station $[3,4,5,6,7,8,9]$. Simulation and a thermoeconomic analysis of several configurations of gas turbine (GT)-based dual-purpose power and desalination plants (DPPDP) has been done in detail [10]. Exergoeconomics has been used as a design tool for the realization of a gas turbine power plant principle [11]. The strategy 
International Journal of Recent advances in Mechanical Engineering (IJMECH) Vol.4, No.4, November 2015

for optimizing the thermal system using the exergetic cost theory and symbolic exergoeconomics has been explained in detail by many researchers $[12,13]$.

\section{METHODOLOGY}

The methodology adopted for the current study is explained with the help of the flowchart given in Fig. 1.

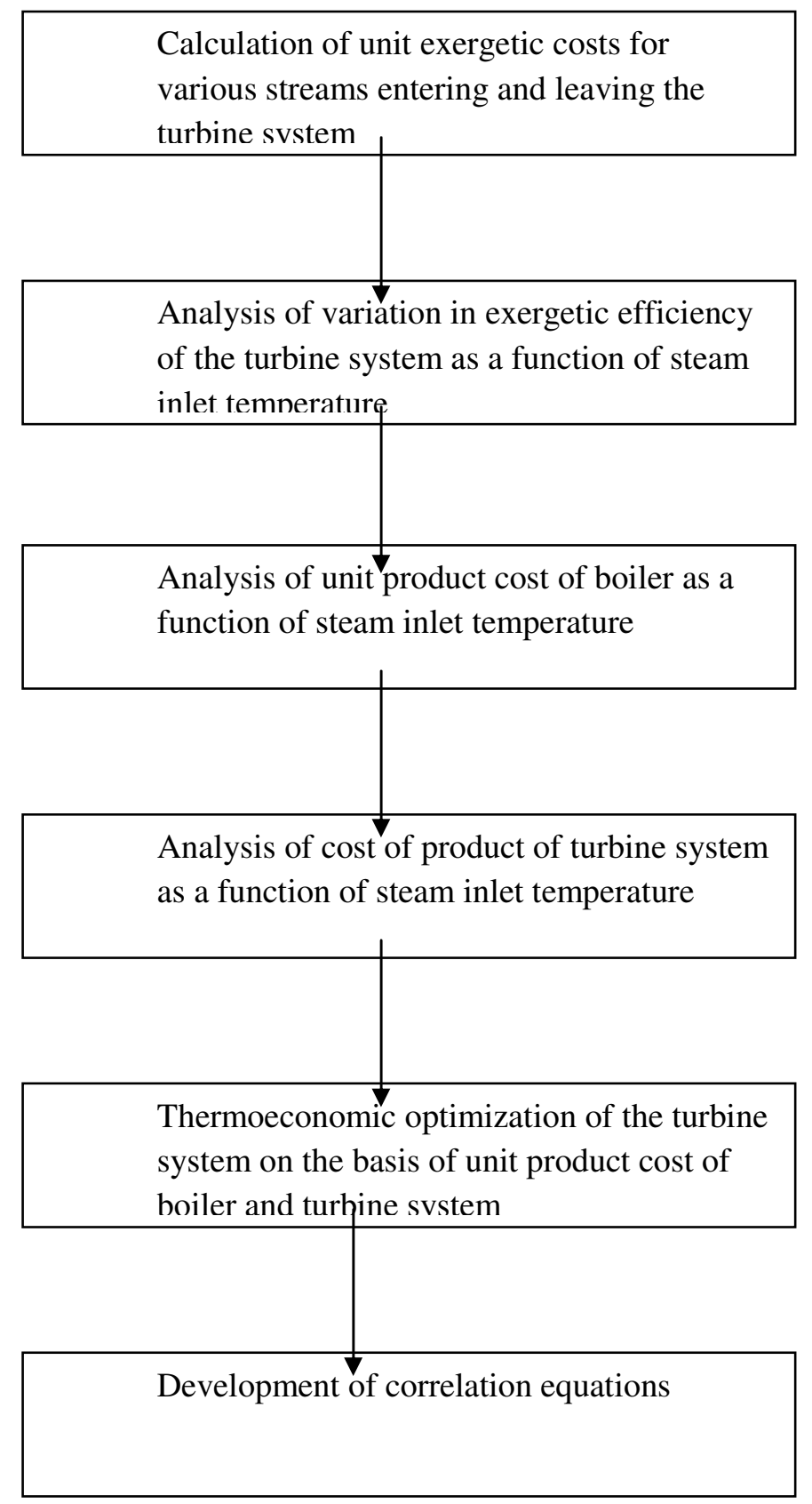

Figure 1. Flowchart depicting the methodology adopted in the current study 


\subsection{Turbine system}

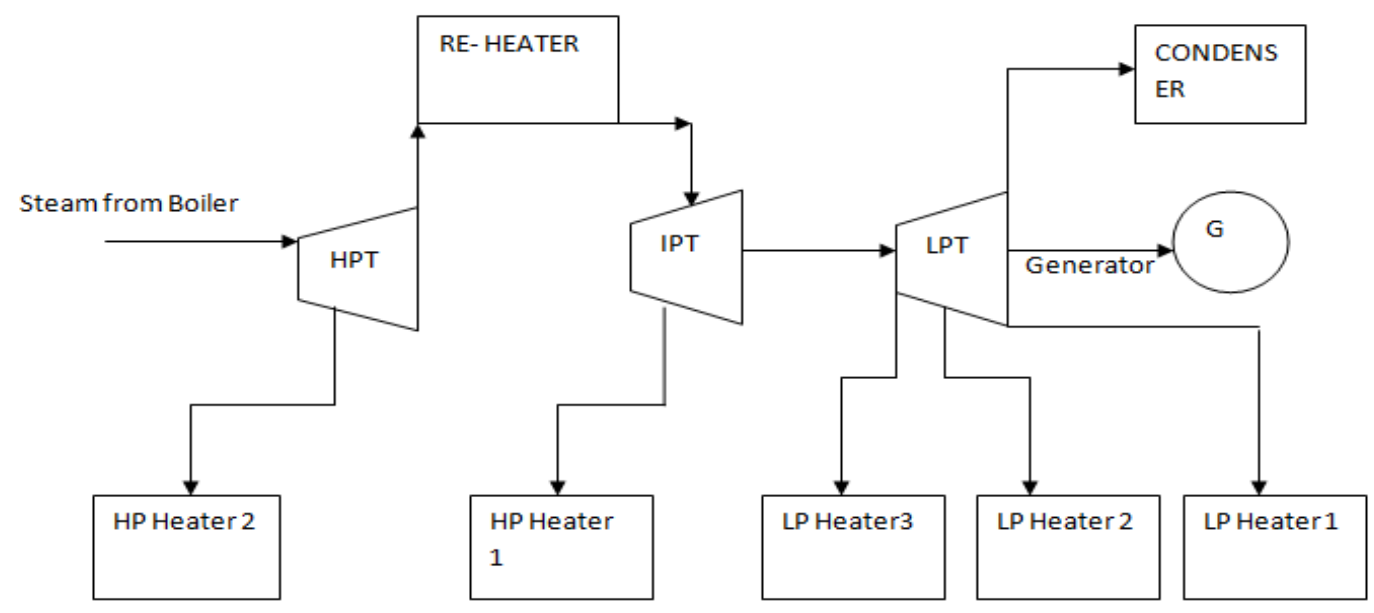

Fig. 2 Schematic layout of a turbine system

For analysis purpose the entire turbine system is taken as a single entity and the modified diagram illustrating the different streams leaving and entering the turbine system are shown in Fig. 3.

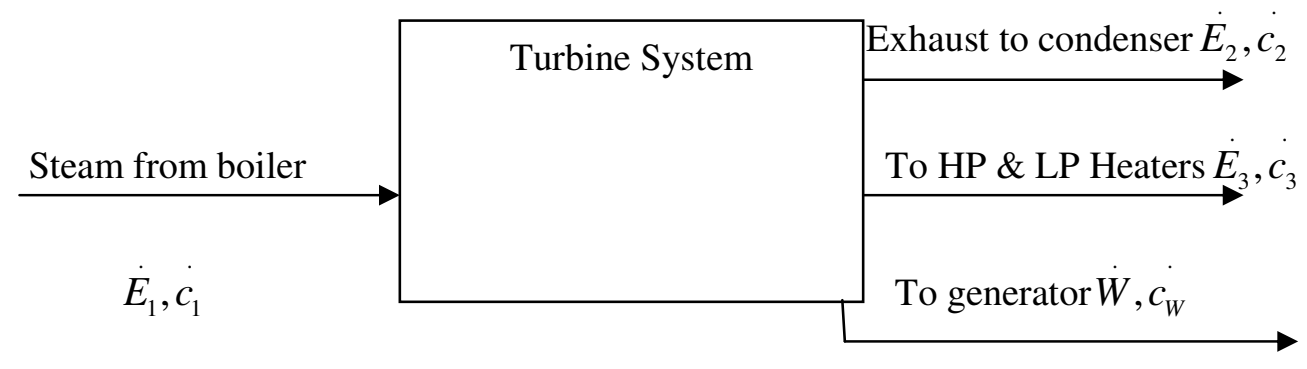

Fig. 3 Different streams entering and leaving the turbine system

\subsection{Exergoeconomic Analysis}

Average costs per exergy unit of fuel and product for a turbine are given as

$$
c_{F, T}=\frac{C_{F, T}}{E_{F, T}}
$$




$$
c_{P, T}=\frac{C_{P, T}}{E_{P, T}}
$$

The exergetic efficiency of a turbine system is given as

$$
\varepsilon_{T}=\frac{\dot{E_{P}}}{\dot{E_{F}}}
$$

The optimization process for the turbine involves the assumption that the exergy flow rate from the turbine is constant.

The exergy costing equation for the turbine system is established as per Fig. (2)

$$
\mathrm{c}_{1} \dot{E}_{1}=\mathrm{c}_{2} \dot{E}_{2}+\mathrm{c}_{3} \dot{E_{3}}+\mathrm{c}_{\mathrm{W}} \dot{W}
$$

From the above equation the unit product cost of turbine system is evaluated as

$$
\mathrm{c}_{\mathrm{W}}=\left[\mathrm{c}_{1} \dot{E}_{1}-\mathrm{c}_{2} \dot{E}_{2}-\mathrm{c}_{3} \dot{E_{3}}\right] / \dot{W}
$$

In the current study all the variables are taken as constant and the effect of inlet steam temperature coming from the boiler on the unit product cost of the turbine system and exergetic efficiency of the turbine system are analyzed.

\section{ILLUSTRATIVE EXAMPLE}

The above said methodology is explained with the help of an example in which a $210 \mathrm{MW}$ power plant is considered. The schematic layout of the turbine system is shown in Fig. 1. For the turbine system under consideration, the values for various unit exergy costs are calculated as per Fig. 2 and are given in Table 1.

Table 1. Values of unit costs for different streams for the turbine system

\begin{tabular}{|c|c|c|}
\hline S. NO. & STREAM NO. & Unit exergy cost (c) (Rs/ MJ) \\
\hline 1 & 1 (Steam from boiler) & 0.7629 \\
\hline 2 & 2 (Exhaust to condenser) & 0.7629 \\
\hline 3 & 3 (Steam bled to different heaters) & 0.7629 \\
\hline 4 & W (Energy transferred to generator) & 1.1907 \\
\hline
\end{tabular}

The unit exergetic costs of streams entering the feed water heaters and condenser is taken to be same as the input cost of fuel [14]. 


\section{RESULTS AND DISCUSSION}

The first step in the thermoeconomic process is to study and analyze the effect of inlet steam temperature on the exergetic efficiency of the turbine system. This is shown in Fig. 4. Exergetic efficiency is seen to increase with an increase in the inlet steam temperature as at higher steam inlet pressure energy available to run the turbine will be high, which in turn will reduce the steam consumption in the turbine.

The second step is to study and analyze the variation of unit product cost of boiler with changes in the inlet steam temperature. This is shown in Fig. 5. The unit product cost of boiler is found to increase with the increase in the inlet steam temperature as providing steam at higher temperatures would require more capital investment.

The final step in the thermoeconomic process is to study and analyze the variation of unit product cost of turbine system with inlet steam temperature. It is seen that with an increase in the inlet steam temperature the unit product cost of turbine system reduces as less quantity of steam is to be handled, hence the operation and maintenance costs are reduced significantly. This brings the reduction in the overall unit product cost of the turbine system. This is shown in Fig. 6.

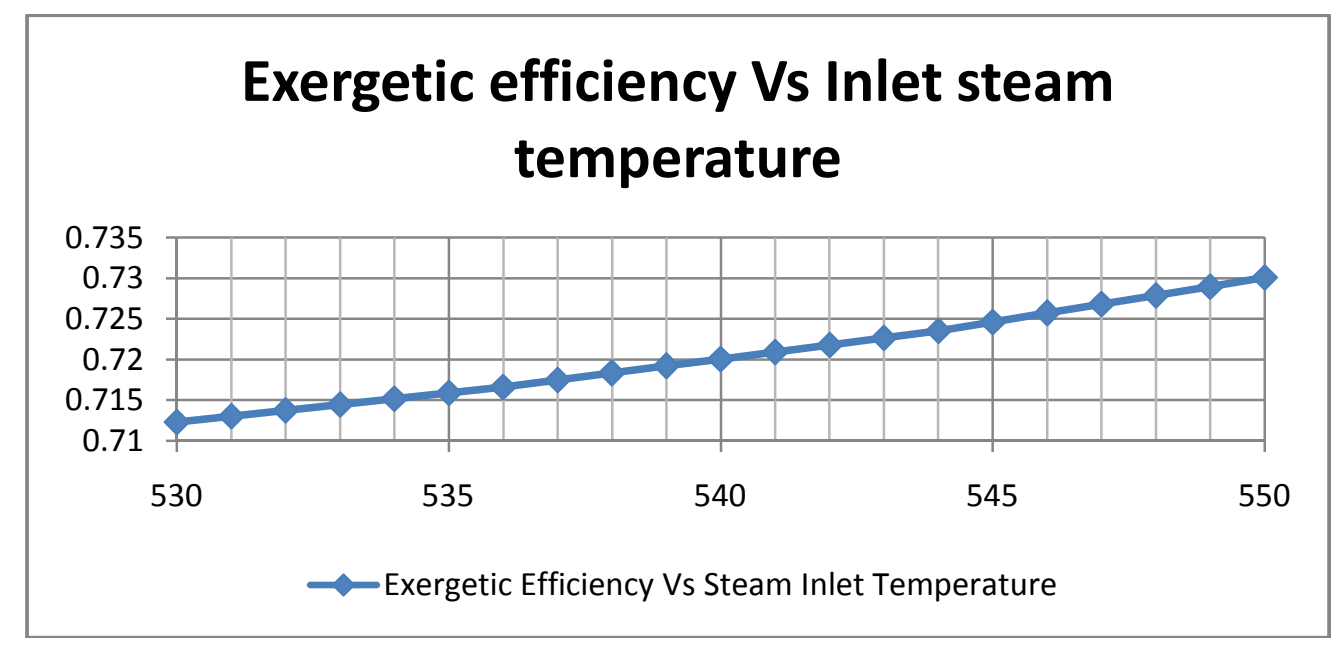

Fig. 4 Variation of Exergetic efficiency with inlet steam temperature 


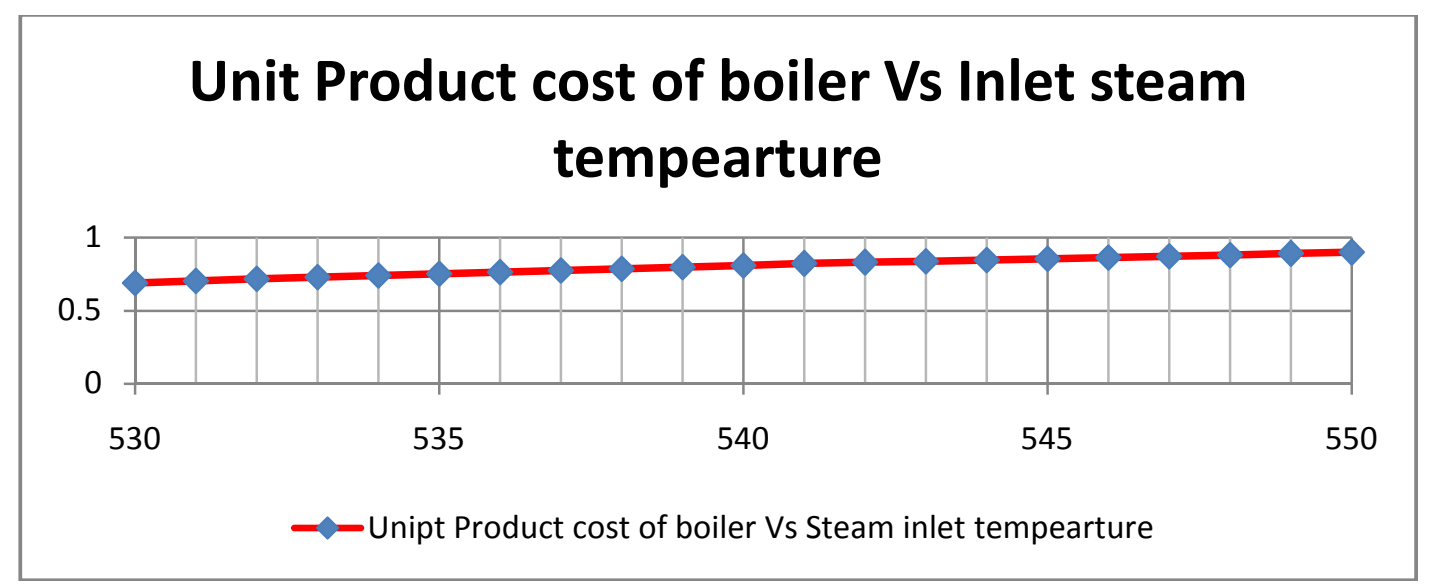

Fig. 5 Variation of unit product cost of boiler with inlet steam temperature

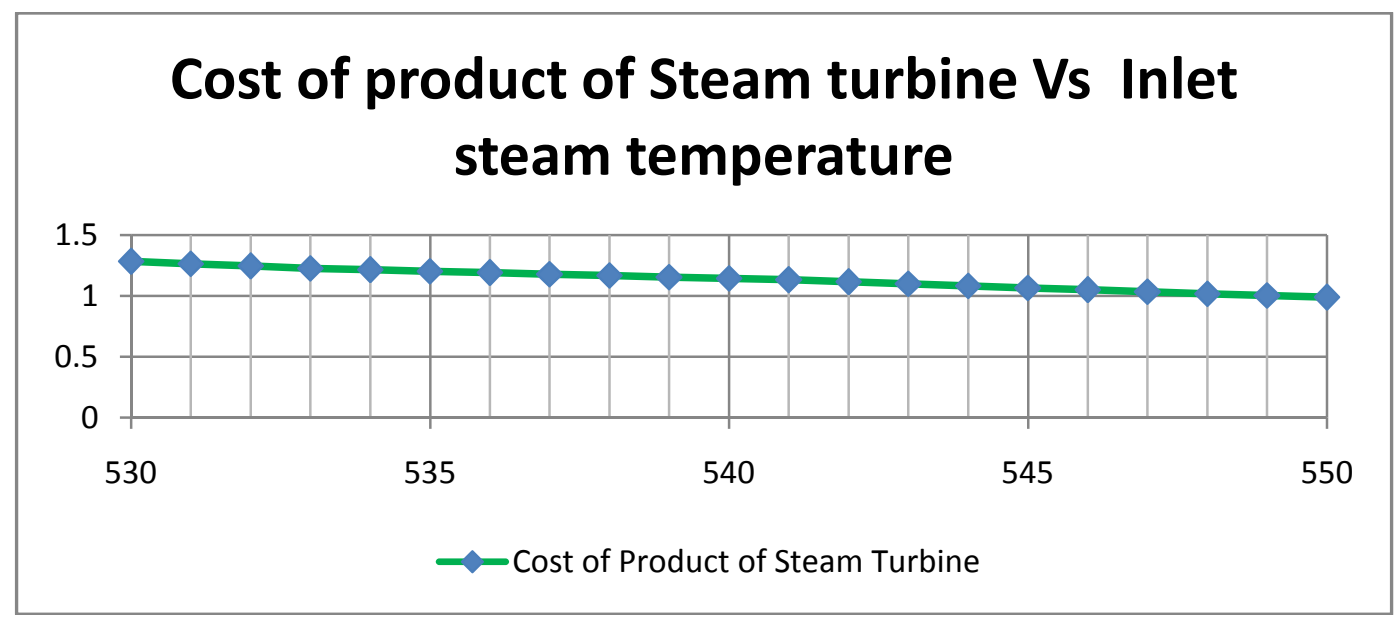

Fig. 6 Variation of unit product cost of turbine system with inlet steam temperature

If we combine the results shown in Fig. 5 and Fig. 6, we find that whereas the unit product cost of the turbine system decreases with an increase in the inlet steam temperature, the unit product cost of boiler increases. Hence to arrive at the optimal value of inlet steam temperature, we combine the results of Fig. 4 and Fig. 5, to arrive at the optimal state. These results are shown in Fig. 7. 
International Journal of Recent advances in Mechanical Engineering (IJMECH) Vol.4, No.4, November 2015

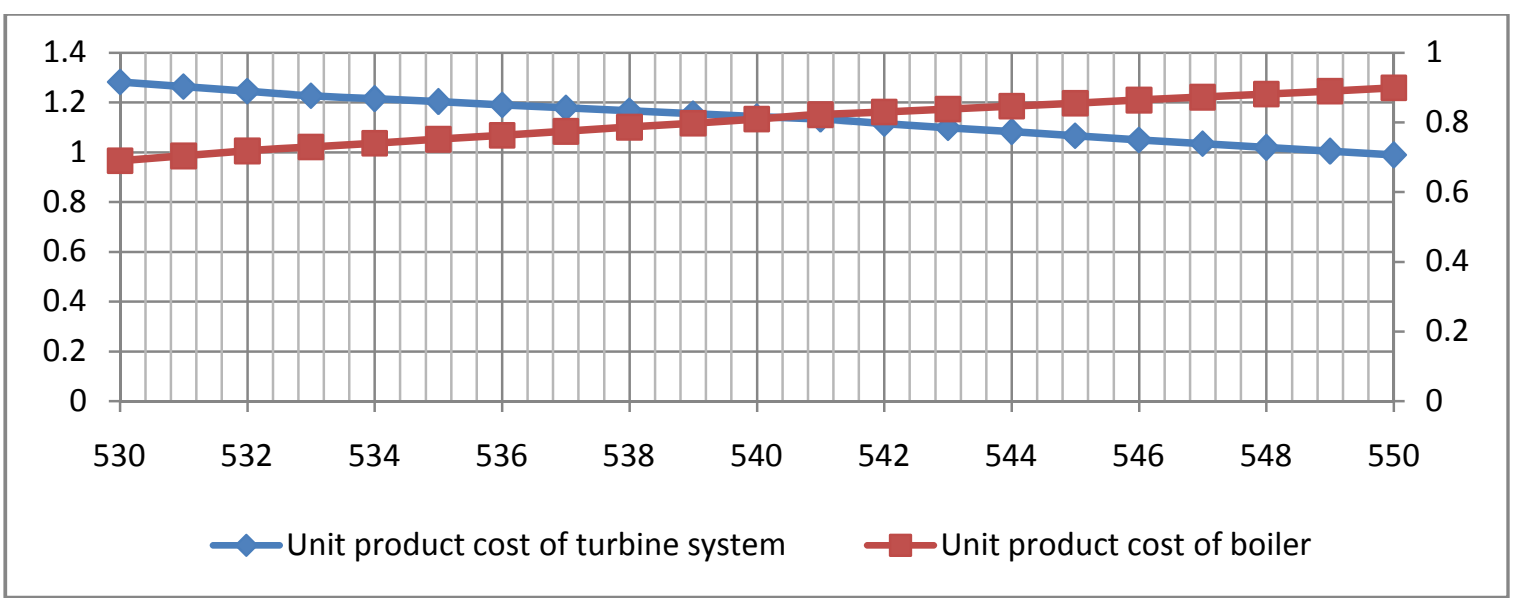

Figure 7. Combined effect of inlet steam temperature on unit product cost of boiler and turbine system

From Fig. 7 it can be seen that the optimal state occurs at $540^{\circ} \mathrm{C}$ at which the unit product cost of the turbine system is $1.1437 \mathrm{Rs} / \mathrm{MJ}$ and the unit product cost of the boiler is $0.80971 \mathrm{Rs} / \mathrm{MJ}$. If further reduction in unit product cost of the turbine system is to be achieved more money would have to be spent on providing inlet steam at higher temperatures. Hence, the overall unit product cost of the power generation system would increase.

The following relations have been derived from the current study, which put forward the exergetic efficiency of the turbine system, unit product cost of turbine system and unit product cost of the boiler as a function of inlet steam temperature.

$$
\begin{aligned}
& \mathcal{E}_{T}=0.3724\left(1.0012^{T}\right) \\
& c_{T}=822.925\left(0.9879^{T}\right) \\
& c_{B}=0.0004\left(1.0141^{T}\right)
\end{aligned}
$$

These relations have been tested for different ranges of temperature values and results have been fairly satisfactory.

\section{CONCLUSIONS}

This study puts forward a novel approach to analyze the performance of a turbine system with respect to inlet steam temperature. Inlet steam temperature has a significant effect on the performance of the turbine system, as has been shown by this study. Thermoeconomic parameters such as unit exergetic cost of turbine system and boiler have been analyzed. These provide a basis for arriving at the optimal value of inlet steam temperature.

Further exponential relations have been developed which prove very useful in calculating the values of the costs and exergetic efficiency for the turbine system. This study provides an excellent basis for analyzing the performance of a turbine system. 


\section{REFERENCES}

[1] Karaali R., Ozturk I. T. (2015) Thermoeconomic optimization of gas turbine cogeneration plants, Energy, Volume 80, Pages 474-485.

[2] Arsalis A. (2008) Thermoeconomic modeling and parametric study of hybrid SOFC-gas turbinesteam turbine power plants ranging from 1.5 to $10 \mathrm{MWe}$, Journal of Power Sources, Volume 181, Issue 2, Pages 313-326.

[3] Rosen M., (2002) Clarifying thermodynamic efficiencies and losses via exergy, Exergy International Journal, 2, 3-5.

[4] Rosen M., (2001) Editorial-Exergy in industry: Accepted or not? Exergy, An International Journal, 2, 67.

[5] Rosen M., (2001) Energy and Exergy based comparison of coal fired and nuclear steam power plants, Exergy International Journal, 3, 180-192.

[6] Rosen M., (2002) Energy crisis or exergy crisis?, Exergy, An International Journal, 2, 125-127.

[7] Rosen M. and Dincer I., (2003) Thermoeconomic, Analysis of power plants: an application to a coal fired electrical generating station, Energy Conversion and Management, 44, 2743-2761.

[8] Valero A. and Torres C., (2004) On causality in organized energy systems: II. Symbolic exergoeconomics, University of Zaragoza, Spain.

[9] Valero A., Lerch F., Serra L. and Royo J., (2002) Structural theo-ry and thermoeconomic diagnosis: Part II, Application to actual power plant, Energy Conversion and Management, 43, 1519-1535.

[10] Rensonnet T., Uche J., Serra L. (2007) Simulation and thermoeconomic analysis of different configurations of gas turbine (GT)-based dual-purpose power and desalination plants (DPPDP) and hybrid plants (HP), Volume 32, Issue 6, Pages 1012-1023.

[11] Valdes M., Duran M. D., Rovira A., (2003) Thermoeconomic optimization of combined cycle gas turbine power plants using genetic algorithms, Applied Thermal Energy, Volume 23, Issue 17, December 2003, Pages 2169-2182.

[12] Attala, L., Facchini, B., Ferrara, G. (2001) Thermoeconomic optimization method design tool in gassteam combined plant realization, Energy Conversion and Management 42 18, pp. 2163-2172.

[13] Mishra R.D., Sahoo P.K. and Gupta A., (2002) Application of exergetic cost theory to LiBr/H2O vapour absorption system, Energy, 1009-1025.

[14] Bejan A., Tsatsaronis G. and Moran M., (1996) Thermal Design and Optimization, New York: Wiley. 